\title{
De El entenado a $E l$ río sin orillas: destitución subjetiva y materialidad del significante en la obra de Juan José Saer
}

\author{
El entenado and El río sin orillas: subjective destitution and the \\ materiality of the signifier in the work of Juan José Saer
}

David Parra Miranda Pontificia Universidad Católica de Chile diparra@uc.cl

\section{Resumen}

La obra de Juan José Saer es conocida por su atención sobre el lenguaje como materialidad productiva y constituyente. Productiva, porque es principalmente desde el lenguaje desde donde habitamos un mundo (El entenado). Constituyente, porque es el lenguaje es una autonomía material, sonora y significante, que nos descentra respecto de nuestros imaginarios (El río sin orillas). Este artículo plantea los alcances antropológicos, ideológicos y literarios de las reflexiones propuestas por Juan José Saer.

Palabras clave: Juan José Saer, significante, materialidad, lenguaje.

\begin{abstract}
The work of Juan José Saer is known for his attention on language as productive and constituent materiality. Productive, because it is mainly from the language from where we inhabit the world (El entenado). Constituent, because it is language is a material, sonorous and significant autonomy, that decentrates us from our imaginaries (El rio sin orillas). This article presents the anthropological, ideological and literary scope of the reflections proposed by Juan José Saer.
\end{abstract}

Keywords: Juan José Saer, signifier, materiality, language.

Recibido: $10 / 08 / 2020$

Aceptado: 10/08/2021

\section{Introducción}

No sería exagerado afirmar que El entenado y El río sin orillas son dos versiones de un mismo libro hipotético. Un libro sobre lo real, su propio real. También, un libro imaginario, cuyo proyecto es abrir un claro en "la selva de lo Real" (Saer, El concepto 219). De ahí que el río y sus orillas sean el escenario de ambos textos: la 
ciénaga quimérica en que chapotearon los primeros conquistadores, el espejismo de los espejismos de la nación argentina. ${ }^{1}$ Los dos lados de este libro hipotético son también los dos lados de la escritura. Como en la "figura de paralaje", ${ }^{2}$ miramos un mismo núcleo problemático desde la prosa ensayística (El río sin orillas) y desde la narración novelesca (El entenado). La figura se complica, como un quiasmo, porque el ensayo se titula tratado imaginario: prosa que se asume ficticia; y la novela, por su lado, como una crónica antropológica, como una suerte de ensayo sobre los caníbales. ${ }^{3}$ Propongo, como hipótesis de lectura, que en ambas obras hay un despliegue de una materialidad significante, tanto en sus formas como en sus contenidos, o, dicho de otro modo, una inscripción de lo imposible — a saber, lo real en sentido lacaniano- en la textura de ambas obras. De acuerdo con esto, ambos textos pueden ser leídos como dos versiones que bordean un mismo impase estructural.

El río sin orillas, extraño libro, es una extraña mezcla de ensayo y algo de autobiografía, un libro que contiene "un poco de todo, como cuando abrimos el cajón de un mueble viejo y encontramos, entremezcladas, reliquias que se asocian al placer o a la desdicha" (17), que no se reduce al formato del "reportaje, ni el del estudio, ni el de la autobiografía" (17). Se trata de un libro hecho de afectos e inclinaciones artísticas: "un híbrido sin género definido, del que existe, me parece, una tradición constante en la literatura argentina —o en mi modo de interpretarla" (17). Por otro lado, El entenado, extraña novela en forma de crónica, ${ }^{4}$ que roza en lo ensayístico,

1 Como señala Florencia Abbate, El entenado "está inspirado en un fragmento de un texto historiográfico que funciona como hipotexto no explicitado por el relato. Se trata de un párrafo de la Historia argentina (1973) de José Busaniche, en el cual el historiador se refiere a la llegada del conquistador español Juan Díaz de Solís al Río de la Plata en 1516.. . Busaniche dedica unos pocos renglones a contar la historia de Francisco del Puerto, quien era el grumete de esa expedición. Este joven se salvó de la muerte, pero fue capturado por la tribu, y habría permanecido cautivo durante diez años, hasta el momento en que llegó la expedición al mando de Sebastián Gaboto, que lo descubrió y lo trasladó de vuelta a España" (12).

2 "La confrontación de dos perspectivas estrechamente vinculadas entre las cuales no es posible ningún campo neutral común” (Žižek. Visión de paralaje 11-2).

3 Como ha destacado Beatriz Sarlo, este diagrama intertextual también se evidencia en la relación entre El río sin orillas y Las nubes, específicamente en la figura de Alfred Ebelot ("Aventuras. . ." 36).

4 Adscribo a la idea de Florencia Abbate acerca del error de catalogar esta novela como "novela histórica": "la idea de que la narrativa intenta ser la trasgresión de la versión "oficial" de la historia tendió a volverse una interpretación mecánica y difusa, estereotipada y con poco contenido; y en el caso de Saer, obtura la originalidad que presenta $\mathrm{El}$ entenado en su modo de representar la historia. Un modo que, desde mi perspectiva, no se puede leer a partir de una tradición realista" (14). O, al menos, de la tradición realista que no ha incorporado las críticas a la mimesis representacional, como sí lo han hecho las obras "realistas" (a su modo) de las últimas décadas en Argentina. Sobre esto último véase el trabajo de Sandra Contreras. Por otra parte, respecto a la cuestión del género de esta novela, Sarlo agrega en "De la 
nos cuenta un relato de orfandad. "El hijastro" o "nacido antes" que, despojado de toda sustancia simbólica, queda en una zona de indeterminación antropológica que solo se resuelve a través de la escritura.

\section{E1 entenado: el nacido antes o la destitución subjetiva}

Julio Premat, en su extenso estudio La dicha de Saturno (2002), afirmaba que la obra de Saer ha sido poco comprendida hasta hace no mucho tiempo y fue relativamente dejada de lado por la crítica de fines de siglo XX, por la presencia de dos conceptos denostados: sujeto y obra (8). Premat proponía releer a Saer bajo una reconsideración de esas dos categorías. Tomo aquí esa consideración de Premat y planteo que esa "sola y única novela", es decir, su "obra", supone, a la vez, un texto imposible, ${ }^{5}$ o un texto de lo imposible, cuya única legibilidad resulta a través de una trama de repeticiones, figuraciones y detenciones. ${ }^{6}$

voz al recuerdo": "El entenado es una fábula filosófica" (314), y sería un error catalogarla como "novela histórica" (314). Más adelante aclara en qué sentido entiende lo de "fábula filosófica": "Si se dijera que sus novelas son filosóficas, habría que aclarar que lo son más a la manera de Musil que a la de Thomas Mann. Problemas filosóficos y estéticos, preguntas sobre si es posible una representación de la realidad, antes que planteados en los diálogos aparecen como performance del relato" (315).

5 Utilizo este término en un sentido muy particular y en diálogo con la obra de Premat. Premat propone que en la obra de Saer existe una "dinámica de autorreferencialidad interrogativa, de corte melancólico" (225). La "obra" de Saer, es decir, el corpus de textos que contienen unidad espacial, recurrencias temáticas, etc., poseería un claro sustrato melancólico. Premat intenta mantener cierta ambigüedad en su uso del término para no reducir su análisis a una descripción psicopatológica, considerando que la melancolía es un concepto general del que se sirven distintas tradiciones (96). Para él, lo inexpresable sería una marca definitoria del texto melancólico (110). Sin embargo, me interesa destacar en este artículo un aspecto distinto de la melancolía: su relación con lo imposible. En Estancias (1995) Agamben sugiere una relectura de la melancolía, de la que extraigo lo siguiente: "la melancolía no sería tanto reacción regresiva ante la pérdida del objeto de amor, sino la capacidad fantasmática de hacer aparecer como perdido un objeto inapropiable" (53). La "ambición ambigua" del proyecto melancólico, es decir, su ambigua relación con la imposible apropiación del objeto perdido supone la apertura de un espacio de apropiación "con la que ninguna posesión podría parangonarse". Dicho de otro modo, "la melancolía logra apropiarse del propio objeto solo en la medida en que afirma su pérdida" (54). De acuerdo con esto, sugiero un paso de lo inexpresable a lo imposible, es decir, leer a Saer como una teoría material de lo Real del lenguaje, de lo imposible en el lenguaje, y no como un lamento melancólico -dichoso o no- de lo inexpresable o inefable. En este sentido, el "texto imposible" es también aquel que virtualmente se inscribiría a lo largo de la obra de Saer, como un objeto que aparece en cuanto inconsistente.

6 Respecto de la escritura de Saer, Kohan ha señalado: "Parece difícil leerlo sin ensayar, de alguna manera, cierto arte de la detención en la lectura, porque hay un arte de la detención en su escritura también. Conviene leerlo despacio: dosificar" ("Testimonios y lecturas" 809). El propio Saer introduce una reflexión acerca de la detención, específicamente de la interrupción, en su cuento "La tardecita": "Existe siempre durante el acto de leer un momento, intenso y plácido a la vez, en el que la lectura se trasciende a 
En el caso de El entenado, se trataría de un replanteamiento de la cuestión del sujeto y la trama textual histórica que lo sostiene. De ahí que esta obra tenga una aproximación hacia "lo real" (Garramuño 712). Pero, considero, no a lo real como "realidad", sino a lo real del lenguaje, a saber, su inscripción material en el sujeto. Por lo mismo, no se trata de leer esta obra como un señalamiento de la inconmensurabilidad de la experiencia de lo real. ${ }^{7}$ Más bien, la leo como el intento de sustraer el vacío que componen los encadenamientos simbólicos culturales, es decir, la experiencia de lo real es, también y principalmente, el conjunto de encadenamientos simbólicos, torcidos y desfigurados, que dan nombre a una falta productiva. En otras palabras, todo El entenado es, justamente, la afirmación positiva de la experiencia de la escritura en torno a un núcleo ausente. Lo real es, entonces, la experiencia siempre móvil, deseante e inconsistente de una imposibilidad constitutiva, punto de arranque de toda experiencia (melancólica) del mundo.

Por su parte, Beatriz Sarlo (2017) ha señalado la imposibilidad de seguir leyendo a Saer desde la teoría del personaje, pues corresponde a una lectura fechada. De acuerdo con Sarlo, considero que la obra de Saer no solo se desmarca de una teoría psicopática ingenua del personaje para pasar a una idea de la "muerte del sujeto/ personaje", sino que repiensa la relación entre el sujeto y el lenguaje de un modo que, a mi juicio, estaría más cerca de una teoría lacaniano-materialista que de la tradición signada bajo el nombre de "postestructuralismo". ${ }^{8}$

sí misma, y en el que, por distintos caminos, el lector, descubriéndose en lo que lee, abandona el libro y se queda absorto en la parte ignorada de su propio ser que la lectura le ha revelado: desde cualquier punto, próximo o remoto, del tiempo o del espacio, lo escrito llega para avivar la llamita oculta de algo que, sin él saberlo tal vez, ardía ya en el lector" (71). El procedimiento de la detención hace que el tiempo sea un objeto relevante en el relato. Sobre esto Sarlo ha señalado: 'La trama cuyo 'tejido verdadero' desconocemos se extiende en el tiempo que es uno de los prodigios de la representación saeriana. Nadie como él ha puesto el tiempo como materia misma del relato" "“Una poética de la incertidumbre" 307). Sarlo retoma esta idea en Zona Saer, donde destaca la "detención y la lentitud descriptiva" (101), elementos que serían el "estilo mismo de Saer" (101).

7 Adscribo a la definición que Lacan entrega de lo Real en su Seminario XX: "Lo real no puede inscribirse sino como un impase de la formalización" (Seminario XX112).

8 Como señala Anna Kornbluh: "This affinity between literature and the Real has not been a proper object of psychoanalytic literary criticism, largely because of Anglo-American habits of lumping together incommensurate French traditions under the rubric of poststructuralism. Prominent outlines of twentieth-century theory routinely beatify the poststructuralist "trinity" of Lacan, Foucault, and Derrida, naming Lacan "properly poststructuralist (...). The general tendency to assimilate Lacan to a rubric of poststructuralism propounds a version of the subject-of-the-signifier that reduces the subject to ideation and ego, omitting Lacan's crucial concerns for the contingency and materiality of the subject and thus fundamentally losing sight of the Real" (Kornbluh 31). En este sentido, adscribo a este deslinde de la teoría lacaniana respecto de la tradición catalogada como "postestructuralista" (que, además, en sí es 
Los primeros versos de "Tabaquería" dicen: "No soy nada/ Nunca seré nada/ No puedo querer ser nada/ Aparte de esto, tengo en mí todos los sueños del mundo" (Pessoa 312). Esta es, quizás, una de las mejores definiciones literarias de la “destitución subjetiva”.9 El entenado tendría, analógicamente, una matriz de sentido parecida. La obra está narrada en la forma de un largo racconto, ambientada en el siglo XVI, en la que un hombre viejo cuenta su juventud como marino hasta su captura por una tribu de caníbales. Todos sus compañeros mueren por el ataque de la tribu, excepto él, quien es capturado como rehén y obligado a vivir con los caníbales como un prisionero peculiar. Es tratado con respeto, como si se tratase de un hombre sagrado, una materialidad que excede el universo simbólico de los caníbales, pero que complementa como un testigo. El lenguaje incomprensible de los caníbales, quienes no paran de repetir, para todo tipo de actividad, la palabra def-ghi, comienza a borrar las huellas simbólicas del origen del narrador protagonista. En un gesto impredecible, el hombre es devuelto a su tierra natal, sin embargo, ha perdido la capacidad de comunicarse. Poco a poco comienza a incorporarse al mundo y comienza un viaje junto a una compañía de teatro representando una obra, precisamente, sobre su experiencia con los caníbales. El recuerdo de su estadía con los indios motivará la escritura de sus memorias, que es la novela que leemos in extrema res.

Metafóricamente, la novela da cuenta de una muerte (y la vida) en el lenguaje. Ahora, ¿de qué se trata esta muerte en el lenguaje? Habría que comenzar por el estatuto particular que posee este "entenado". Entenado es nacido antes (literalmente ante natus). Se refiere, específicamente, a aquellos que son hijos de otra familia, a los hijastros. Son aquellos a quienes la historia les ha impuesto otro orden simbólico familiar-cultural. Ese desajuste entre órdenes simbólicos distintos, entre el paso de una ley a otra, es la brecha que presenta al sujeto, cual vacío incluido y excluido del lenguaje. Cabe señalar la traducción al inglés de esta novela: The witness, el testigo. Pero ¿testigo de qué? De un crimen fundamental: el cosido del sujeto con el lenguaje, la entrada al orden simbólico. El entenado, en su errancia y orfandad, logra ver separado lo que parecía naturalmente reunido. Saer nos presenta la fábula del sujeto, de ahí que el narrador personaje ni siquiera tenga nombre.

ya una reducción) y, en este sentido, propongo una lectura de Saer desde esta bifurcación y no desde la "muerte del sujeto" que Sarlo, acertadamente, despacha.

9 Proceso en el que el analizante renuncia "al apoyo de las identificaciones imaginarias y/o simbólicas" para "asumir plenamente el vacío de la subjetividad (\$)". En este proceso hay una identificación "con el objeto a, el resto no-simbolizable del proceso de simbolización; al reconocer en este "excremento" el soporte único de su ser" (Žižek Metástasis... 215). 
Tal como en "el banquete totémico, acaso la primera fiesta de la humanidad, sería la repetición y celebración recordatoria de aquella hazaña memorable y criminal con la cual tuvieron comienzo tantas cosas: las organizaciones sociales, las limitaciones éticas y la religión" (Freud, Totem y tabú 143-4), la novela de Saer también nos propone un mito fundacional. ${ }^{10}$ Se trata de un mito acerca de la muerte de la Cosa por la palabra, muerte inmemorial a la que se llega una y otra vez:

Mi vivir había sido como expelido de mi ser, y por esa razón los dos se me habían vuelto oscuros y superfluos. A veces, me sentía menos que nada — si por sentirse nada entendemos la calma bestial y la resignación; menos que nada, es decir caos lento, viscoso, indefenso, cuya lengua es balbuceo, y que por ser justamente menos que nada y por no poseer ni siquiera la fuerza ajena del deseo, se debate en el limbo espeso y como ciego del desprecio de sí mismo y de los sueños de aniquilación (El entenado 150).

Un vivir expelido del ser, es decir, una vida fuera del marco regulativo del lenguaje de la ciudad. Menos que nada, destitución que ni la calma ni la resignación pueden colmar. Esta experiencia de destitución supone un borde en el que se (des) encuentran el narrador y los indios Colastiné. Por ejemplo, respecto de los indios, nos dice el narrador:

El deseo con que los contemplaban asarse era el de una experiencia antigua incrustada más allá de la memoria. . Sabían, en el fondo, que como lo exterior era aparente, no masticaban nada, pero estaban obligados a repetir, una y otra vez, ese gesto vacío para seguir, a toda costa, gozando de esa existencia exclusiva y precaria que les permitía hacerse la ilusión de ser en la costra de esa tierra desolada, atravesada de ríos salvajes, los hombres verdaderos (183).

Para ellos, "ese mundo que parecía tan sólido, había que actualizarlo a cada momento para que no se desvaneciese como un hilo de humo en el atardecer" (172). Los caníbales no se comen al narrador, pero sí devoran, en cierto modo, su existencia.

Saer escenifica una experiencia de desencuentro radical: una "antropología antinarcisista”, ${ }^{11}$ por tomar el concepto de Viveiros de Castro: el narrador se deja con-

10 Esta "escena primordial" es retomada por Saer en El río sin orillas.

11 "A fuerza de ver siempre al Mismo en el Otro — de decir que bajo la máscara del otro es "nosotros" lo que nosotros mismos contemplamos-, terminamos por contentarnos con acortar el trayecto que nos conduce directamente al final y no interesarnos más que en lo que "nos interesa", a saber, nosotros 
vertir por esa materialidad (in)significante con la que tropieza. Es transformado radicalmente a través del encuentro con la alteridad absoluta. El narrador es destituido de todo anclaje simbólico, develándose así su insustancial materialidad. ${ }^{12}$ Este aparente oxímoron se explica de la siguiente forma: el sujeto es la nada que habita el orden simbólico, cuya consistencia nula estructura nuestra realidad. ${ }^{13}$

Esta sensación de extrañamiento frente al lenguaje es descrita por el narrador en su experiencia con la compañía de teatro:

En el escenario del teatro. . . veía a mis compañeros y a mí mismo repetir gestos y palabras de las que estaba ausente lo verdadero. Pero esa impresión, que todos tenemos alguna vez, es aunque intensa, pasajera. . . Un día cuando menos nos lo esperábamos, nos asalta súbita; durante unos minutos, las cosas conocidas se muestran independientes de nosotros, inertes remotas a pesar de su proximidad. Una palabra cualquiera, la más común, que empleamos muchas veces por día, empieza a sonar extraña, se despega de su sentido, y se vuelve ruido puro. . . cuanto más repetimos la palabra más extraña y desconocida nos suena (150).

Esta vertiginosa inmaterialidad de la realidad, o bien, su profunda materialidad insustancial, es presentada por Saer como un "desastre arcaico" del que los indios se defienden a toda costa. Vivían — no deja de señalarnos el narrador- aferrados a ese pequeño trozo de realidad que aseguraba su existencia. Y es esta inexistencia la que es tan ominosa para el narrador, quien ve a través de todas sus especulaciones nada más que las condiciones de su propio descentramiento. El narrador asume su discurso como inexacto, como una ficción antropológica más, pero en la que se revela una inconsistencia ontológica radical. Es una apertura en el Ser lo

mismos. Por el contrario, una verdadera antropología nos devuelve de nosotros mismos una imagen en la que no nos reconocemos. . lo que toda experiencia de otra cultura nos ofrece es una oportunidad de realizar una experimentación sobre nuestra propia cultura; mucho más que una variación imaginaria, una puesta en variación de nuestra imaginación" (Viveiros de castro 15).

12 Para aproximarse al tópico de la materialidad desde una perspectiva bachelardiana, véase el excelente ensayo de Rafael Arce "Un realismo de lo irreal: la imaginación material en la obra de Juan José Saer".

13 Sobre la realidad y la irrealidad, véase el ensayo de Alberto Giordano "El efecto de irreal" acerca de la obra de Juan José Saer. Dice Giordano: "Disimulado por la familiaridad de las palabras, lo que en verdad nos inquieta de la realidad ( $\mathrm{y}$ es en esa dimensión inquietante en la que quiere captarla la literatura) es su extrañeza, su presencia inhumana, la indiferencia absoluta con que recibe cualquier calificación" (31). Esta extrañeza es categorizada por el autor como lo "irreal": "Lo irreal, que no presupone otras convenciones, otras certezas diferentes a las que estamos acostumbrados, que no se deja confundir ni con lo "maravilloso" ni con lo "mágico", no es otra realidad sino, más bien, lo otro de la realidad, lo que, para constituirse, la realidad niega, enmascara: el vacío que es el corazón de nuestras evidencias, el enigma en que nuestras certezas se fundan" (33). 
que la novela intenta ilustrar: apertura que el espacio entre-dos-muertes posibilita, es decir, ese "paradójico reino entre lo vivo y lo muerto" (Dolar 6, la traducción es mía), entre lo simbólico y lo Real. Dicho de otro modo, el proceso de destitución que atraviesa la obra tanto temática (lo narrado) como formalmente (la narración) da cuenta de lo real de la subjetividad, es decir, la relación inconsistente entre el sujeto y sus ficciones, entre el puro vacío de la enunciación y los enunciados.

La relación entre escritura y memoria es también un eje importante en la novela. ${ }^{14} \mathrm{El}$ ejercicio mismo de la escritura es un elemento presente dentro del propio del texto, "en la noche silenciosa, la mano que escribe se detiene, y en el presente nítido, casi increíble, me resulta difícil saber si esa vida ha tenido realmente lugar, llena de continentes, de mares, de planetas y de hordas humanas o si ha sido, en el instante que acaba de transcurrir, una visión causada menos por la exaltación que por la somnolencia" (212). En otro lugar, el narrador nos dice: "Recuerdos y sueños están hechos de la misma materia. Y, bien mirado, todo es recuerdo" (El entenado 211). Esta relación con el pasado que se dibuja, sobre todo hacia el final del texto, supone una reconsideración de la realidad y la ficción. Al extremar dicha relación, el recuerdo, equiparado al sueño, adquiere una materialidad o realidad, mientras que la realidad recupera cierto carácter de artificio. ${ }^{15} \mathrm{El}$ pasado, parece sugerirnos el narrador, no está conformado de hechos inamovibles, sino de textos con los que hemos significado nuestra historia. ${ }^{16}$

Por otra parte, los caníbales de Saer están despojados de todo el imaginario monstruoso. El horror ominoso que suscitan es de otro orden: son unos caníbales neuróticos, si se quiere, empecinados en mantener ritualmente todas las piezas del edificio de la realidad para no desvanecerse: "Querían hacer persistir, por todos los medios, el mundo incierto y cambiante. Malgastar una flecha, por ejemplo, era para ellos como desprenderse de un fragmento de realidad. Arreglaban todo y siempre barrían y limpiaban" (174). A su vez, estos indios neuróticos necesitan alguien que

14 Para una discusión acerca de la escritura, la mimesis y el tema del doble en El entenado, véase Díaz-Quiñones, Arcadio. "El entenado: Las palabras de la tribu". Hispamérica 63 (1992): 3-14.

15 Un cuento de Saer que desarrolla esta relación entre artificio, sueño y realidad de manera magistral es "En línea", parte del libro Lugar.

16 Lacan propone una fórmula para esto: "la historia no es el pasado, la historia es el pasado historizado en el presente, historizado en el presente porque ha sido vivido en el pasado" (Seminario I 27). Punto que Freud supo dilucidar de su análisis del caso del "hombre de los lobos" respecto a la realidad de la "escena primordial" contada por el paciente: "tengo el propósito de cerrar este examen del valor de realidad de las escenas primordiales mediante un «non linquet)" ("El hombre de los lobos" 57). Esta misma intuición, Borges la formuló así: "El pasado es arcilla que el presente labra a su antojo" ("Todos los ayeres, un sueño" 535). 
atestigüe su propia humillación existencial. Dice el narrador: "Amenazados por todo eso que nos rige desde lo oscuro, manteniéndonos en el aire abierto hasta que un buen día, con un gesto súbito y caprichoso, nos devuelve a lo indistinto, querían que de su pasaje por ese espejismo material quedase un testigo y un sobreviviente que fuese, ante el mundo, su narrador". Esta lógica de cómo lo Uno deviene Dos (por usar un término de Badiou), encuentra su análogo en la relación entre analista y analizante: "The analyst is not there to judge, punish or praise the subject, or insist on right answers or sympathize or even understand, she is there to witness the patient's humiliation at encountering herself" (Aristodemou 116). Dialéctica de un desencuentro entre dos horizontes simbólicos que solo se tocan en su fracaso. Sin embargo, esta destitución supone también la posibilidad de reconocimiento del Otro ya no desde las identificaciones narcisistas, sino desde la asunción de esta insustancialidad compartida, de lo Real del otro, antes de toda constitución imaginaria y/o simbólica. Es en este puro vacío del sujeto donde quedamos totalmente iguales.

El def-ghi de los indios, insistente y meloso, ilustra en una suerte de ironía borgeana, lo aleatorio del significante, pero también su dimensión trágica. Def-ghi es el fragmento material con el que pueden sostener y anudar la realidad: "Era una lengua imprevisible, contradictoria, sin forma aparente. Cuando creía haber comprendido el significado de una palabra, un poco más tarde me daba cuenta de que esa misma palabra significaba también lo contrario, y después de haber sabido esos dos significados, otros nuevos se me hacían evidentes, sin que yo comprendiese muy bien por qué razón el mismo vocablo designaba al mismo tiempo cosas tan dispares" (172). En ese idioma de los indios, no hay ninguna palabra que equivalga a ser o estar, la que más se le acerca significa parecer: pues "para los indios -dice el narrador- todo parece y nada es. Y el parecer de las cosas se sitúa, sobre todo, en el campo de la inexistencia" (173). Los indios se avergonzaban de su inexistencia. $Y$ es esta inexistencia la que se le devuelve al narrador, es esa brecha que se abre y que desarticula lo que aparenta estar unido naturalmente, a saber, la relación entre el orden simbólico y el sujeto.

Lo que Saer elabora en su "antropología especulativa" ${ }^{17}$ o caníbal, es la presentación de esta dimensión material del significante, el estar muertos en la Letra y

17 "La masa fangosa de lo empírico y de lo imaginario, que otros tienen la ilusión de fraccionar a piacere en rebanadas de verdad y falsedad, no le deja, al autor de ficciones, más que una posibilidad: sumergirse en ella" (El concepto 12). La obra de ficción sería, entonces, un sistema especulativo de símbolos culturales compuestos en una zona indefinida, no reducible a las categorías de lo verdadero, lo falso o lo verosímil. Para un estudio detallado sobre esta noción de "antropología especulativa" en la obra de Saer, véase 
su Ley. Lo que Saer-caníbal haría con el lector es quitarle (comerle) ese precioso tesoro de la vida - es decir, la creencia ingenua de poder sortear las volteretas del texto inconsciente que nos compone- recordándonos aquella dimensión de entenados, desajustados y muertos por el lenguaje y su atolladero pulsional. Se trata de una relación nueva entre la vida y la muerte: "No se sabe cuándo se nace: el parto es una simple convención. Muchos mueren sin haber nacido; otros nacen apenas, otros mal, como abortados. Algunos, por nacimientos sucesivos, van pasando de vida en vida, y si la muerte no viniese a interrumpirlos, serían capaces de agotar el ramillete de mundos posibles a fuerza de nacer una y otra vez, como si poseyesen una reserva inagotable de inocencia y abandono" (45). Tal como la palabra mata la Cosa ${ }^{18}$ nosotros, a través del bautismo mortuorio del lenguaje, estamos muertos. Sin embargo, la verdadera pregunta políticamente materialista sería entonces: "¿hay vida después de la muerte?”.

\section{E1 sujeto sin orillas: toponimia de la subjetividad argentina}

El río sin orillas es un texto de clasificación compleja. La crítica ha señalado que se trata de un tema con el que Saer lidia en sus textos narrativos y ensayísticos. ${ }^{19}$ Saer se resiste a la clasificación de ensayo y prefiere la denominación "tratado imaginario", debido a la estrecha relación entre este texto y el resto de su obra narrativa (Torres 88): "Es como si Saer regresara sobre el tema de El entenado con un lenguaje distinto y una reflexión de tipo generalizante en torno a esa suerte de escena que considera fundadora del Río de la Plata" (89). Planteo que este retorno a lo que traza en El entenado, es al modo de un negativo fotográfico: se trata de un texto estrechamente ligado a la reflexión sobre el vacío constitutivo de la subjetividad, pero ahora con un énfasis en el conjunto de saberes, dichos, enunciados y textos que componen la red simbólica que dicho sujeto sutura. ${ }^{20}$

Riera, Gabriel. "La ficción de Saer: ¿una "antropología especulativa”? (Una lectura de El entenado)". The Johns Hopkins University Press. Hispanic Issue 111 (1996): 368-390.

18 "Así el símbolo se manifiesta en primer lugar como asesinato de la cosa, y esta muerte constituye en el sujeto la eternización de su deseo" (Lacan 306).

19 'A diferencia de esos ensayos 'propiamente dichos', relativamente breves, muchos de los cuales pasan en limpio las ideas de Saer sobre narración, El río sin orillas no se sale del cauce narrativo de su obra ni se distingue de un mismo 'repertorio' de textos en los que la prosa alberga la reflexión y la iluminación poética" (Lucero 681).

20 Por sutura entiendo lo que Jacques-Alain Miller plantea: "La sutura nombra la relación del sujeto con la cadena de su discurso: ya veremos que él figura en esta como el elemento que falta, bajo la forma de algo que hace sus veces. Pues faltando en ella, no está pura y simplemente ausente. Sutura, por extensión, la relación en general de la falta con la estructura de la que es elemento, en tanto que implica la posición 
Ahora bien, ¿cómo elabora Saer este retorno? Lo que El entenado parece esbozar como una tesis sobre el lenguaje, el significante y su materialidad, encuentra forma plena en El río sin orillas. Bajo la solicitud "de construir un objeto significativo", Saer busca y examina, en sus afectos e inclinaciones artísticas, residuos sugestivos de lo que constituye una tradición constante de - o en- la literatura argentina. Estos residuos son significantes ${ }^{21}$ históricos y subjetivos que, por su manera de conectar y motivar los eventos, representan un nuevo campo de experiencia, ese "colectivo singular" (Koselleck 45) que es la tradición argentina. A través de un análisis de los discursos, significantes y toponimias, Saer intenta desentrañar la "escena primitiva" colectiva, que funda las coordenadas discursivas que darán forma a distintas prácticas sociales y políticas durante el siglo XX. La mitología del hombre argentino como alguien excepcional desembocará en lo que, en opinión de Saer, es uno de los grandes desastres de la vida social y política argentina: el peronismo.

El río sin orillas propone una interrogación de las capas discursivas que los distintos grupos sociales hegemónicos han impuesto, contribuyendo a la conformación del mito nacional argentino. Para el autor, uno de estos grupos influyentes en el siglo XX es la clase media: "los más irrazonables fantasmas sobre la esencia de la sociedad argentina fueron impuestos a todas las capas sociales por la clase media: que éramos un país rico, una sociedad pacífica, que en nuestro país no hay racismo, que hay libertad de religión, que el que no progresa es porque no quiere trabajar, etc." (170). El ritmo pulsional de esta clase ha marcado la historia del siglo XX: mitos personales que una clase ha instalado en el fundamento de la nación, pero también discursos colectivos, fantasías de una épica del ser argentino.

¿Cuáles son estos discursos y significantes que han cristalizado en un mito de autorrepresentación nacional? Para responder, el autor examina lo que denomina la "escena primitiva" 22 del Río de la Plata: espacio y tiempo donde se sedimentaron

de algo que hace las veces de él" (55). Luego agrega: "El objeto imposible que el discurso de la lógica convoca como lo no-idéntico consigo mismo y rechaza como lo negativo puro, que convoca y rechaza para constituirse como lo que es, que convoca y rechaza no queriendo saber nada de él, lo llamamos, en tanto que funciona como el exceso que opera en la serie de los números: el sujeto" (62).

21 Suscribo aquí a la definición elaborada por Gérard Pislor: "El significante, en el sentido psicoanalítico, implica la conjunción de una letra y un movimiento del cuerpo. En el análisis de El hombre de los lobos, $\mathrm{V}$ solo es significante en la medida en que marca un movimiento libidinal del cuerpo (abertura de los ojos, boca, etc.)" (98, la traducción es mía). Agradezco esta referencia a Roberto Hozven.

22 Sobre la "escena primitiva", Saer relata: "Es la desproporción de lo que Solis y sus hombres pensaban de sí mismos y la función [ritual] que le atribuyeron los indios al comérselos crudos en la playa misma en que los mataron - la escena primitiva de la historia del Río de la Plata_, caricatura del relativismo cultural, lo que vuelve al hecho impensable en su desmesura y vagamente cómico a causa del malenten- 
discursos y fantasías en torno al ser argentino. Escena primitiva que ha quedado reprimida, pero que retorna en nombres, prácticas e imaginarios nacionales. Mitologías discursivas naturalizadas y enraizadas en lo más profundo de la sociabilidad argentina. El río sin orillas presenta una enumeración que va desde los nombres de ciudades, pasando por los variados matices de color del Río de la Plata, tipos de árboles en los patios argentinos, tipos de peces del río, descripciones hiperbólicas y desmesuradas acerca de la pampa por los primeros viajeros y cronistas europeos, hasta llegar a las convulsiones políticas y a la violencia de Estado en el siglo XX en los periodos de Perón (1946-52, 1952-55, 1973-74).

El Río de la Plata plantea un problema de entrada para el escritor, debido a la cantidad de discursos que hay sobre él: "hay tantos Ríos de la Plata como discursos se profieren sobre él" (El río... 22) y, al igual que en la máxima de Heráclito acerca de la imposibilidad de entrar dos veces en el mismo río, "cada uno trata de entrar, infructuoso, como en un sueño, en su propio río" (23). La primera aproximación de Saer destaca un elemento singular del Río de la Plata: la imposibilidad de observar su otra orilla. La voz narrativa se ve en medio de una quietud silenciosa que imposibilita cualquier descripción: "la experiencia directa no había funcionado: tenía que resignarme a la erudición. Así va el mundo, la cosa parece próxima, inmediata, pero hay que dar un rodeo largo para llegar a rozarla, siquiera fugazmente, con la yema de los dedos. Nada de lo que nos interesa verdaderamente nos es directamente accesible" (32). Entonces, el único modo de tocar ese esquivo objeto es a través del autoexamen de las propias experiencias y textos que conforman su historia subjetiva, desde un dicho popular hasta los lejanos relatos de los primeros cronistas. No hay discurso erudito objetivo posible: Saer se reconoce un objeto más de su propio discurso, permeado de la cultura que desea describir.

El Río de la Plata es una expresión que designa la zona pampeana y, a veces, "sinécdoque para referirse a la Argentina entera" (El río... 39). En su origen, fue denominado Mar Dulce por Juan Díaz de Solis, quien lo descubrió en 1516, luego llamado "río de Solis" y finalmente "de la Plata", por las supuestas riquezas que se suponía albergaba (54). El Río de la Plata es "el nombre de una quimera" (111): la fantasía de los conquistadores proyectada sobre ese terreno baldío. Las desventuras de los primeros descubridores y conquistadores dejaron una serie de nombres

dido brutal de dos sistemas de pensamiento" (El río... 54). Con esta expresión, Saer está por supuesto refiriendo a las ideas de Freud en Tótem y Tabú: "El banquete totémico, acaso la primera fiesta de la humanidad, sería la repetición y celebración recordatoria de aquella hazaña memorable y criminal con la cual tuvieron comienzo tantas cosas: las organizaciones sociales, las limitaciones éticas y la religión" (Freud, Tótem... 143-4). Agrega Saer, para hacer más patente la referencia: “el descubrimiento del Río de la Plata acabó en un banquete caníbal" (El río... 171). 
que fueron configurando un espacio de incertidumbre. Saer destaca el hecho de que, desde los primeros años de la conquista, todos estaban "de paso" por el Río de la Plata, "nadie tenía la menor intención de instalarse" (58). Esta situación, nos dice Saer, "persistirá hasta nuestros días en muchos sectores de la población, por causas diversas y asumiendo formas diferentes, y ha influido en la constitución de nuestra sociedad, de nuestra cultura, de nuestras costumbres, de nuestras emociones y de nuestra economía" (58).

Uno de los temas a los que el autor dedicará varias páginas es la toponimia: nombres de los lugares que configuran un mapa, real e imaginario, del Río de la Plata y la pampa argentina:23 "En el Río de la Plata, y en América en general, la toponimia oscila entre lo simbólico y lo sensorial. Los nombres religiosos de los españoles y los nombres femeninos de los inmigrantes del siglo XIX alternan, en la superficie coloreada de los mapas, con los que evocan la inmediatez de las sensaciones" (106). Así, la toponimia indígena confundirá los planos simbólicos y sensoriales. Por ejemplo: Paraná, "padre de ríos", describe tanto su corriente poderosa como su curso atormentado. Esta toponimia está relacionada a lo sensorial, es decir, al gesto más inmediato de nombrar de acuerdo con los sentidos:

Vista, oído, gusto, tacto, olfato, sirvieron para clasificar para siempre los cursos acuáticos. . Pero en la mayoría de los casos, es la pura impresión de los sentidos. . .: El río Negro, el Colorado, el Bermejo, el río Verde, el Blanco, los ríos Grande y Chico, lo mismo que el río Seco o la laguna mar Chiquita perpetúan impresiones visuales; los ríos Dulce, Salado, Saladillo, Amargo, el río Agrio, gustativas (107).

Saer ofrece una larga lista con nombres de este estilo, sugiriendo una proliferación que se extiende hasta lo incontable. En algunos casos, esta toponimia tiene resonancias inesperadas: "En la provincia de Río Negro, por ejemplo, hay un cerro que se llama Cain, enfrente de otro que se llama Dos Hermanos, y ambos forman un triángulo con un tercero que, como por casualidad, tiene el nombre de Dos Amigos. Un hecho misterioso que nos parece adivinar emana de esos nombres" (110). Este ejercicio de nombrar la realidad encuentra su límite en una "denominación genérica extrema" en la zona sur: el cabo Nombre.

23 Cabe destacar lo que Piglia ha dicho de Saer: "en ningún otro escritor. . . es tan pertinente la relación entre la ficción y la cartografía como en Saer. La ficción es una cartografía" (Piglia citado en Abreu 161). 
Sobre este fenómeno, el autor intenta sensibilizar al lector sobre la relevancia material de los nombres. Para él, la toponimia "representa a decir verdad la primera constelación verbal que se despliega en la superficie atormentada del universo, proyectiles verbales lanzados por el aliento codificado del hombre" (110). En el caso del Río de la Plata mismo, el autor señala:

Ese espejismo en que chapotearon [los primeros conquistadores] sirvió para nombrar al país entero, la Argentina, gracias a un deslizamiento poético, más neoclásico que clásico, consistente en llamar primero al agua turbulenta, valiéndose de un epíteto, el argentino río, feminizándolo un poco más tarde, las argentinas aguas, y aplicándolo por fin al territorio circundante, la argentina tierra" (110).

Se trató de un "abuso verbal flagrante" porque en todo el territorio no hubo ni un gramo de ese metal. Más adelante, el autor ahonda su reflexión acerca de la toponimia y señala:

Los nombres, por lacónicos, y aun impenetrables que sean, son el primer texto que leemos sobre, y la preposición nunca ha sido más literal, un país, y a menudo únicamente los nombres existen para muchas cosas. . . sobre todo con la parte interna de nuestro propio cuerpo, reticulado por una toponimia minuciosa que no deja en el anonimato ni la más oscura terminación nerviosa (111).

Saer acuña la expresión "guerras toponímicas" para dar cuenta cómo en el plano del significante se liberan batallas según los intereses de distintos grupos. En los gobiernos argentinos, señala el autor, se borra con todo lo anterior: "cambian no únicamente los ministros y los legisladores (que a decir verdad desaparecen lisa y llanamente) sino también muchos empleados públicos, cambian los proveedores del Estado. . . los animadores de televisión y las estrellitas de moda, los obispos y los traficantes de droga, los directores de diario e incluso los diarios. . ." (114). El ejemplo más extremo de esto estaría en el gobierno de Perón, quien se dedicó a cambiar nombres de avenidas, hospitales, provincias y monumentos por los de Perón y Evita, en todas sus variantes posibles.

A juicio del autor, las mejores páginas que se han escrito sobre Argentina han sido por extranjeros (102). Esto es especialmente relevante si se considera la incidencia de estos relatos extranjeros en el forjamiento de la identidad argentina. En esta gama de discursos foráneos, quizás el más llamativo y acertado sea el dictum de Darwin, 160 años antes de la fecha en que Saer escribe, y que tiene resonancias 
siniestras para la historia argentina. Dice Darwin, citado por Saer: "Y el pueblo espera todavía poder establecer una república democrática a pesar de la ausencia de todo principio en los hombres públicos y mientras el país rebalsa de oficiales turbulentos24 y mal pagos" (100). Junto a las acertadas palabras de Darwin, hubo otros discursos menos acertados, más fantasiosos, que contribuyeron al mito de la identidad argentina:

El frenesí geográfico y seudotecnológico que se apoderó de Europa a mediados del siglo XIX, en pleno auge colonialista, y que empezó a decaer hacia 1930, suministró toneladas de páginas abominables. En cualquier librería de viejo de Londres o París los libros sobre Las pampas, El Río de la Plata, o La América del sur pululan, igualmente insípidos, y en muchos casos a la primera ojeada se adivina que sus autores, o bien no han salido de Buenos Aires más que para ir a comer un asado a una estancia vecina, o han hecho una escala de 48 horas en algún crucero (104).

Se trata de construcciones mitológicas que se han petrificado en la nación y que han producido una fuerte alienación en los propios argentinos, quienes han construido un yo desde el espejo europeo.

El clima de la pampa también es otro tópico por el que se han filtrado estas motivaciones ideológicas. Respecto del modo en que los primeros viajeros europeos registraron literariamente el clima, por ejemplo, el autor señala: "El buen tiempo nunca es un banal día agradable, sino 'el clima más templado y benéfico que la Providencia haya tenido la bondad de otorgar a comarca alguna en la tierra"' (136). Lo mismo con Buenos Aires: "A veces, las confusiones semánticas, una especialidad regional, originan interpretaciones climáticas y temperamentales, verdaderamente inesperadas, como en esa enciclopedia francesa de la primera mitad del siglo XIX en la que su autor, un tal César Famin, persiste en el error de creer que el nombre de Buenos Aires es una consecuencia de su clima agradable" (137). Nombre que en realidad proviene de una virgen andaluza, Santa María del Buen Aire, patrona de los marineros, cuya resonancia católica desajusta el imaginario de la nación laica.

La fauna tampoco queda fuera de estas fantasías extranjeras. Sobre los tigres, Saer nota un hecho curioso en los registros del viajero Chaworth Musters: "En esa descripción, su libro, excelente en casi todo, incurre en un curioso rasgo de oscurantismo: como un tigre se abstiene de atacar y matar a sus perseguidores, lo

24 Cabe destacar cómo el significante "turbulento" utilizado para referirse al Río de la Plata reaparece aquí para señalar a los oficiales. 
trata de degenerado, en razón, podemos suponer, de que el animal se obstinaba en no amoldarse a la idea preconcebida que tienen los exploradores ingleses de esa rama de los felinos" (139). Esta extraña afirmación encuentra su conclusión ridícula en lo que otro viajero señaló: “después de argumentar sobre la poca afición de los tigres por la carne humana, nos dice que en realidad lo que los atrae por encima de todo es comerse a los negros, en segundo lugar a los indios y por último, y solo en casos de extrema necesidad, al hombre blanco" (140).

Saer atribuye a la pampa y su inmensidad el espacio ideal para las proyecciones de la imaginación, para la construcción superlativa y oportunista del espacio, lo que conformó los cimientos del mito argentino. La historia argentina sería, para el autor, el resultado de una serie de capas discursivas que se han ido sedimentando desde la llegada de los europeos: un país conformado de fantasías propias y extranjeras. Su reflexión apunta al:

hecho más universal de que la mayoría de nuestras supuestas percepciones son meras proyecciones imaginarias. . Darwin se refiere al 'aspecto de grandeza que se cree encontrar obligatoriamente en una vasta llanura', sugiriendo de ese modo la influencia que las ideas preconcebidas tienen en nuestras percepciones. A lo que vemos, sumamos en una misma operación mental lo que recordamos, sabemos o imaginamos (120).

Todo lo anterior supone que se debe "meditar sobre los resortes fantasmáticos de toda escritura, aun aquella que nace de la convicción más firme acerca de los privilegios de lo empírico" (140). Estos resortes fantasmáticos, o motivaciones ideológicas, estuvieron posibilitados por las características reales de la pampa, es decir, un espacio desnudo, chato, con un cielo desproporcionado (155).

El espacio de la pampa supuso un obstáculo importante en el siglo XIX. En el intento de hacer avanzar la civilización hacia la pampa, se crea el proyecto de "la zanja de Alsina", ideado por Alfred Ebelot ${ }^{25}$ para la "Conquista del sur". Este proyecto consistía en un sistema defensivo hecho de fosas de cien leguas, fortificadas, cuya función era impedir el avance de los indios. En medio del antagonismo bélico entre los indios y el gobierno nacional, la figura de Ebelot ocupa un lugar extraño, intermedio:

su fe entusiasta, por no decir su superstición del progreso, dirigían su interés hacia los aspectos humanos, políticos y sociales de la Argentina, en un pe-

25 Personaje real que encuentra su correspondencia literaria en la novela Las nubes de Saer. 
ríodo de transformaciones violentas y de contrastes vertiginosos: arcaísmo y modernidad, violencia y humanismo, inmigración y pasatismo patriarcal, liberalismo y tiranía, desiertos inconmensurables y salvajes y ciudades que aspiraban a formar parte de la cultura europea (El concepto 69).

Esta única construcción posible en el descampado que era la pampa "no fue más que un reguero intermitente de pozos semiderruidos, en los que al poco tiempo nomás empezó a crecer otra vez el pasto" (74). Este foso persiste en la imaginación argentina como una "curiosidad simbólica": la fe ciega en el progreso desmentida por la ineficacia del foso, representativo de "la verdadera imagen del país por venir" (74). No sin cierta ironía, el autor sostiene que este proyecto fue determinante en dos sentidos: fomentar la literatura fantástica (la idea kafkiana y absurda de construir zanjas de cien leguas para ir encerrando a los indios de la pampa) y constituir el primero de los proyectos inacabados de Argentina: rascacielos a medio construir, puertos a medio terminar, carreteras sin pavimentar, etc. (El río 149).

En El río sin orillas, Saer rescata y analiza algunos significantes que organizan el concepto de experiencia mental del "colectivo singular" argentino, capaces de producir efectos en el entramado simbólico en que habitamos y validamos en nuestras relaciones cotidianas. Propongo entender este ejercicio saeriano desde un marco de comprensión lacaniano. Lacan ha sido uno de los autores que ha pensado el aspecto material del significante, a saber, su indestructibilidad: "todo verdadero significante es, en tanto tal, un significante que no significa nada" (Seminario III 264) y "mientras más no significa nada, más indestructible es el significante" (265). Con esto Lacan enfatiza la preponderancia del significante por sobre el significado, es decir, la capacidad del primero de producir efectos de significado independientes de la voluntad de los interlocutores. Un significante puede despertar asociaciones inesperadas precisamente por su materialidad — de ahí su poderosa capacidad de generar equívocos y despertar relaciones imprevistas-, a diferencia del significado, profundamente soportado por los imaginarios e intencionalidades del yo hablante. El significante rompe con los oportunismos del yo del enunciado. Es esta relevancia e independencia del significante, como cadena que preexiste al sujeto hablante, la que, según mi lectura, operaría en lo que Saer describe en El río sin orillas con su análisis de la toponimia y los discursos que han conformado el imaginario argentino. Cada argentino habita una nación relatada por poderosos imaginarios que se remontan a los orígenes de la nación argentina. 
¿Cómo se relaciona esta proliferación de significantes con el mito de la identidad o autorrepresentación del hombre argentino? Para responder, cabe señalar lo que Lacan explica acerca del significante en el Seminario XI:

Un significante es lo que representa un sujeto cante quién? No ante otro sujeto, sino ante otro significante. Para ilustrar este axioma supongan que descubren en pleno desierto una piedra cubierta de jeroglíficos. No les cabrá la menor duda de que allí hubo un sujeto que los inscribió. Pero creer que todo significante le está destinado a uno es un error, y prueba de ello es que a lo mejor no los entienden. Sin embargo, uno los define como significantes, porque está seguro de que cada uno de estos significantes está relacionado con los demás. Justamente, de esto se trata en la relación del sujeto con el campo del Otro (206).

En este sentido, "el Río de la Plata", tal como la piedra con jeroglíficos descrita por Lacan, constituye un sintagma significante que en sí mismo no significa nada, pero que sí adquiere significación cuando se relaciona con otros significantes. "El río de la plata" configura una cadena de hipérboles: las abundantes riquezas de las tierras argentinas, el exagerado clima benigno de "Buenos Aires", de la inmensidad de la pampa a la avenida Nueve de Julio, "la más ancha del mundo". Es la "hiperbolización cardinal"26 que desemboca en la expresión, tan cotidiana como siniestra, con la que los argentinos parecen solucionar imaginariamente sus dificultades económicas y sociales: “el millón de muertos”27 (Saer, El río... 187).

En cuanto a "la zanja de Alsina", aquella estructura de "pozos semiderruidos", también opera de manera significante, a la manera de la "V" de El hombre de los lobos, ya señalada anteriormente. Estos pozos medievales ideados por Ebelot anteceden todas esas construcciones inacabadas, tan comunes para los argentinos, y que forman una cadena de lo inacabado. En términos políticos, por otro lado, la proliferación de nombres de Perón y Evita en calles, escuelas e instituciones da cuenta de cómo el personalismo o patrimonialismo político inunda la realidad

26 Hiperbolización que remonta a un uso colonial del guarismo, como se lee en Brevísima relación de la destrucción de Indias (1552), de Bartolomé de las Casas, para referir las desmesuras y crueldades cometidas por los españoles en la guerra de conquista y colonización posterior.

27 Sintagma mágico que cumple diversas funciones: "Este millón de muertos es, para el grueso de la opinión pública, la panacea, el recurso mágico que, cuando ninguna salida es en apariencia posible, resolverá todos los problemas. Ante cualquier contrariedad, el argentino medio, ese ser que se considera pacífico y hospitalario, invoca inmediatamente el millón de muertos; si es un chofer de taxi, ese millón de muertos le parecerá la solución más adecuada para terminar con los embotellamientos, si es un jubilado, el único medio para cobrar por fin una justa jubilación” (Saer El río... 187). 
social, precisamente por medio de la materialidad del significante. También aquí parece resonar la significancia de "el río de la Plata", cuyas "turbulentas aguas" remiten a los "turbulentos oficiales" caudillistas — mencionados por Darwin- que se transforman en notables políticos. Así Saer muestra la dimensión inconsciente que "sutura" 28 todos estos significantes en el sujeto argentino. Sus conciencias —nuestras conciencias - operan con materiales que, sin saberlo, los constituyen. Estamos "zurcidos" de modo inconsciente al discurso del Otro, sin haber procesado de modo cabal las presuposiciones del discurso que enunciamos.

Cuando Saer rastrea los encadenamientos significantes que han conformado el mito territorial argentino, intenta hacer aparecer lo real reprimido desde la escena primitiva, signada por el desconocimiento, para el "ser argentino": "El primer paso para penetrar en nuestra verdadera identidad consiste justamente en admitir que, a la luz de la reflexión y, por qué no, también de la piedad, ninguna identidad afirmativa ya es posible" (206). El río sin orillas es la operación de una desnaturalización de los significantes que, anclados a significados oportunistas, han conformado el mito de la identidad argentina. Lo que Saer intenta desentrañar de esta escena primitiva es la incertidumbre o vacilación constitutiva que acompaña todo esfuerzo de aferrar una identidad nacional. Esta indeterminación, que para el autor es un rasgo decisivo en la historia de su país, es lo que posibilitó, según Saer, que un discurso tan delirante como el de Perón pudiera encontrar tanto arrastre: "El 'justicialismo' [de Perón], no era ni comunista ni capitalista, sino que representaba una 'tercera opción', pero en claro no se trataba más que de un menjunje paternalista y populista" (181). La nación como imaginario y mito, por tanto, es un modo de "suturar" los distintos significantes que conviven en la espesura de lo Real. La dimensión ideológica de este mito nacional está en el hecho de que supone una "naturalización del orden simbólico; esto es, como la percepción que reifica los resultados de los procedimientos discursivos en propiedades de la cosa en sí” (Žižek, Ideología 18).29 Su desnaturalización, por tanto, es la tarea que Saer parece asignar al ensayista y/o narrador.

28 Es decir, la inserción del sujeto en la cadena significante con su simultánea exclusión consciente. El hombre argentino actualizaría esta inserción inconsciente/exclusión consciente.

29 Como señala Žižek, el concepto de ideología debe ser "desvinculado de la problemática "representacionalista": la ideología no tiene nada que ver con la "ilusión", con una representación errónea, distorsionada de su contenido social' (Žižek 13). En este sentido, no se trata de que los argentinos, por ejemplo, tengan o no efectivamente "la avenida más ancha del mundo". Lo ideológico estaría en el soporte fantasmático de esta idea. 


\section{Conclusión}

El río sin orillas viene a completar la intuición que Saer despliega en El entenado. Ambos textos dan cuenta de la textura material del significante: en la novela, se trata de la oposición de dos sistemas simbólicos, en el que uno se vacía en el otro, y cuyo punto de juntura es el vacío del sujeto; en el ensayo, se trata de desmontar todas las capas discursivas que constituyen la realidad material del significante, reconocer sus flujos de poder y la suturación imaginaria que las compone. En este sentido, son dos variaciones de un mismo libro imposible: un libro sobre lo Real del lenguaje, sobre su autonomía respecto de nuestras intencionalidades conscientes, pero también como el espacio donde habita el deseo y se despliega la lucha por la transformación de la realidad. Lo Real lacaniano no supone un tipo de inconmensurabilidad de la experiencia del mundo, sino, más bien, que la experiencia del mundo está sostenida, en un grado importante, por un cierto ordenamiento que el lenguaje impone. El sujeto es la brecha que aparece, justamente, en las contradicciones, impases e inconsistencias de esta estructura de símbolos. El sujeto de la escritura saeriana es, justamente, esa inconsistencia de las ficciones totalizantes. Su escritura nos devuelve, al final, la posibilidad de salir de la pregnancia absoluta que toda identidad impone. 


\section{Obras citadas}

Abbate, Florencia. El espesor del presente: Tiempo e historia en las novelas de Juan José Saer. Villa María: Eduvim, 2014.

Abreu, Carlos. "La paternalidad conciliadora de El entenado. Borges, Di Benedetto y la tradición argentina”. Chasqui: revista de literatura latinoamericana 2 (2017): 161 177.

Aristodemou, Maria. Law, Psychoanalysis \& Society. London: Routdledge, 2014.

Borges, Jorge Luis. "Todos los ayeres, un sueño". Obras completas. Buenos Aires: Emecé Editores, 2005.

Freud, Sigmund. "Tótem y tabú". Obras completas. Tomo XIII. 1913. Trad. José L. Etcheverry. Buenos Aires: Amorrortu editores, 1992.

---. "De la historia de una neurosis infantil (el 'Hombre de los lobos')" (1917-1919). Obras completas XVII. Trad. José L. Etcheverry. Ordenamiento, comentarios y notas de James Strachey. Buenos Aires: Amorrortu Editores, S.A., 1992.

Garramuño, Florencia. "Las ruinas y el fragmento. Experiencia y narración en El entenado y Glosa". Saer Juan José. Glosa - El entenado. Poitiers - Córdoba (Argentina): CRLA-Archivos/Alción(ColecciónArchivos, 61)Edicióncrítica, Julio Premat (coord.), 2010. 710-728 Giordano. Alberto. "El efecto de irreal". Discusión, suplemento de crítica literaria de la Revista de Letras 1(1989): 27-35.

Kohan, Martín. “Testimonios y lecturas de escritores”. Dossier de la obra. Saer, Juan José. Glosa - El entenado. Poitiers - Córdoba (Argentina): CRLA-Archivos/Alción (Colección Archivos, 61), 2010.

Koselleck, Reinhart. historia/Historia. 1975. Traducción e introducción de Antonio Gómez Ramos. Madrid: Mínima Trotta, 2010.

Lacan, Jacques. Seminario XX: Aún. 1973. Trad. Diana Rabinovich, Delmont-Mauri y Julieta Sucre. Buenos Aires: Paidós, 2009.

---. "La instancia de la letra en el inconsciente o la razón desde Freud". Escritos I. 1966. Trad. Tomás Segovia y Armando Suárez. Buenos Aires: Siglo XXI Editores, 2013.

---. Seminario XI: Los cuatro conceptos fundamentales del psicoanálisis. 1964. Trad. Juan Luis Delmont-Mauri y Julieta Sucre. Buenos Aires: Paidós, 2010 
---. Seminario III: La psicosis. 1955-1956. Trad. Diana Rabinovich \& Juan Luis Delmont-Mauri. Buenos Aires: Paidós, 2013.

---. Seminario I: Los Escritos Técnicos de Freud (1953-1954). Trad. Rithee Cevasco y Vicente Mira Pascual (revisada por Diana Rabinovich). Buenos Aires: Paidós, 2001.

Lucero, Nicolás. "El ensayo como forma en El río sin orillas de Juan José Saer". Revista Iberoamericana 78 (2012): 681-694.

Miller, Jacques Alain. "La sutura”. 1986. Matemas II. Trad. Carlos A. de Santos. Buenos Aires: Ediciones Manantial, 1994.

Pislor, Gérard. "Le concept psychanalytique de corps (I). (11 janvier 1967)". Cabiers pour l'Analyse 8 (f/f): 97-101. L'impensé de Jean-Jacques Rousseau. Travaux du Cercle d'épistemologie de l'École Normale Supérieure.

Premat, Julio. La dicha de Saturno. Escritura y melancolía en la obra de Juan José Saer. Buenos Aires: Beatriz Viterbo, 2002.

Saer, Juan José. El río sin orillas: tratado imaginario. 1991. Buenos Aires: Seix Barral, 2015.

---. "La tardecita”. 2000. Cuentos completos. Buenos Aires: Seix Barral, 2018.

---. El concepto de ficción. 1996. Buenos Aires: Seix Barral, 2014.

---. El entenado. 1983. Buenos Aires: Emecé Editores, 2005.

Sarlo, Beatriz. "Escribir lo real (conferencia)". Coloquio Internacional Juan José Saer. Santa Fe Cultura. 13 de Mayo, 2017.

---. Zona Saer. Santiago de Chile: Ediciones Universidad Diego Portales, 2016.

---. "Una poética de la incertidumbre". Escritos sobre literatura argentina. Ed. Sylvia Saítta. Buenos Aires: Siglo XXI Editores Argentina, 2007

---. "De la voz al recuerdo". Escritos sobre literatura argentina. Ed. Sylvia Saítta. Buenos Aires: Siglo XXI Editores Argentina, 2007

---. "Aventuras de un médico filósofo. Sobre Las Nubes de Juan José Saer". Punto de vista 59 (1997): 35-38.

Torres Perdigón, Andrea. "El río sin orillas de Juan José Saer y el género literario". Revista de teoria y crítica de la literatura hispanoamericana 5 (2018): 83-102. 
De El entenado a El río sin orillas: destitución subjetiva y materialidad...

David Parra

Žižek, Slavoj. Visión de paralaje. 2006. Trad. Marcos Mayer. Buenos Aires: FCE, 2011.

--- Ideología: un mapa de la cuestión. 1994. Trad. Cecilia Beltrame et al. Buenos Aires: Fondo de Cultura Económica, 2003.

---. Metástasis del goce: seis ensayos sobre la mujer y la causalidad. 1994. Trad. Patricia Willson. Buenos Aires: Paidós, 2005.

Viveiros de Castro, Eduardo. Metafísicas caníbales. Lineas de antropología postestructural. Trad. Stella Mastrangelo. Buenos Aires: Katz Editores, 2010. 